\title{
Nuevos tapabocas para viejas invisibilidades: representaciones de la niñez y adolescencia en medios periodísticos durante la pandemia en Mendoza, Argentina
}

\author{
New masks for old invisibilities: Representations of children and adolescents in the media during the pandemic in
} Mendoza, Argentina

\section{José María Vitaliti}

Instituto de Ciencias Humanas, Sociales y Ambientales - Argentina

Mendoza, Argentina

jmvitaliti@mendoza-conicet.gob.a

\section{RESUMEN}

La niñez y adolescencia en tiempos de pandemia estuvo mayormente confinada. La casa concentró las tareas escolares y la recreación en un mismo espacio. De esta manera, la escuela y las salidas eran espacios en los que transcurría la reproducción de la vida. Si bien, la niñez y adolescencia estaban fuertemente vinculados a estos espacios, la agenda estatal y mediática operaron de manera diferenciadora. En este trabajo se buscó identificar y analizar las representaciones sobre la niñez y la adolescencia en pandemia en la prensa local de Mendoza, Argentina. La metodología utilizada tiene un enfoque cualitativo de corte hermenéutico. Para ello, se trabajó con fuentes periodísticas utilizando una como mojón principal: "Los Andes". Para contrastar y analizar la fuente anterior, se utilizaron fuentes locales "El Otro" e internacionales "El Confidencial”, “Les Echos” y “EI País”. Las categorías emergentes surgidas por medio del análisis fueron: 1. la escuela: virtualidad, desigualdad y deslegitimaciones 2. el confinamiento: cierre de espacios de juego y la adolescencia desconfinada 3. la salud infantil: la vulnerabilidad en los niños/as como aún-no y 4. el femicidio en niñas y adolescentes. Las categorías de infancia fueron regresivas. La niñez y adolescencia como "los aún no" y en clave moderna, son manifestaciones que en tiempos de pandemia continúan siendo sostenidas por una estructura patriarcal y adultocéntrica, que segrega y excluye a la niñez y adolescencia subalternizandola.

Palabras clave: Pandemia; Infancia; Adulto; Estereotipo; Exclusión Social

\begin{abstract}
Children and adolescents in times of the pandemic were mostly confined. The house concentrated school work and recreation in the same space. In this way, the school and the recreation were spaces in which the reproduction of life took place. Although childhood and adolescence were strongly linked to these spaces, the state, and media agenda operated differently. This work will seek to identify and analyze the representations about childhood and adolescence in pandemics in the local press of Mendoza, Argentina. The methodology used has a qualitative hermeneutical approach. For this, we worked with journalistic sources using one as the main landmark: "Los Andes". To contrast and analyze the previous source, local sources "El Otro" and international sources "El Confidencial", "Les Echos" and "El País" were used. The emerging categories that emerged through the analysis were: 1. school: virtuality, inequality, and delegitimization 2. confinement: closing of play spaces and misguided adolescence 3. child health: vulnerability in children as yet- no and 4 . femicide in girls and adolescents. The childhood categories were regressive. Childhood and adolescence as "those not yet" and in a modern key, are manifestations that in times of pandemic continue to be sustained by a patriarchal and adult-centered structure, which segregates and excludes children and adolescents by subalternizing it.
\end{abstract}

Keyword: Pandemics; Childhood; Adults; Stereotypes; Social exclusion 


\section{INTRODUCCIÓN}

A comienzos del año 2020, la población mundial se vió afectada por un virus cuya magnitud de contagio puso en riesgo el estado de salud de sociedad. Debido a esta situación, el 11 de marzo del 2020, la OMS determina que el COVID 19 puede caracterizarse como una pandemia, a causa de los alarmantes niveles de propagación de la enfermedad y por su gravedad.

A partir de esta declaración y por la velocidad en el agravamiento de la situación epidemiológica a escala internacional, el Estado argentino dispuso el ASPO (Aislamiento Social Preventivo y Obligatorio) el 20 de marzo 2020 y con el fin de proteger la salud pública. El ASPO consistió en el confinamiento de todos/as los/as habitantes de la Nación con excepción de los servicios considerados esenciales: salud, seguridad, comercio que abastecieran la población, entre otros. Esta medida sin precedentes, tuvo un alto aceptación, en principio, por la clase política y los medios masivos de comunicación. La sociedad en su conjunto aterrorizada por el "enemigo invisible” e impredecible, acató en su mayoría la norma, más allá que el Estado disponía de la fuerza pública en caso de no cumplimiento debido a la obligación inalienable de proteger la población (Decreto 297/2020, art. 1-4).

El Estado en su carácter Federal consultó la mayoría de las medidas adoptadas con las provincias a través de reuniones periódicas con los gobernadores. Si bien el ASPO era una disposición compartida por la Nación, las particulares geográficas aportaron cierta singularidad en la recepción de las medidas adoptadas.

Atento a ello, la provincia de Mendoza, debido a las tensiones propias de ser un color político diferente al de Nación, aporta una singular manera de tratar las cotidianeidades en clave geográfica e identitaria. Según datos demográficos, la población de Mendoza cuenta con 1.990.330 habitantes. Asimismo, la composición mayoritaria es de sexo femenino (1.011.147 mujeres frente a 979.191 varones). En cuanto a los grupos sociales según la edad, observamos que la franja etaria de 30 a 64 años es la mayor (40\% de la población total). El grupo etario que le sigue son los/as niños/as y adolescentes de o a 19 años con el 32\% de la población total. Mientras que jóvenes (16\%) y viejos (12\%) tienen los varemos más bajos en relación a la población total. Por lo tanto, de acuerdo a lo planteado, podemos sintetizar que la población mendocina es predominantemente femenina y la composición etaria plantea una mayoría para los/as adultos/as (dos de cinco) y, en segundo lugar, los niños/as y adolescentes (un tercio de la población total de Mendoza) (INDEC, 2013).

Teniendo presente que la niñez y adolescencia, representa un importante sector en relación a la población total de la provincia, nos preguntamos: ¿Cómo transitaron los/as niños/as y adolescentes el confinamiento en esta geografía? ¿Cuáles fueron las experiencias vividas en pandemia que pudieron ser rescatados por los adultos/as y las instituciones garantes de sus derechos? ¿Qué papel tuvo la corresponsabilidad comunitaria frente a recorte de proximidades frente a la guerra con el virus?

Para cartografiar la matriz de acciones alrededor de las infancias, es importante visibilizar las miradas sociales en torno a la infancia. Es decir, en palabras de Alcubierre Moya (2018) cuál es la construcción de significados en torno a la niñez (tan cambiante como la propia sociedad moderna), aquello que ella llama "representación de la infancia”.

Según Ferrán Casas (2005) en investigación sobre las representaciones sociales y las infancias, argumentan que las "infancias que podemos observar a nuestro alrededor son "otra cosa" que las infancias que nos representamos" (p. 41). Por otro lado, y consonancia con lo expresado con 
el autor, Fernández Ruiz (2021) realiza un estudio sobre la población infantil y la educación virtual en pandemia, y los caracteriza como "nativos pandémicos". Este concepto de la división conocida entre nativos e inmigrantes digitales proveniente de Prensky (2001). Esta característica estudiada plantea diferencias con las miradas actuales sobre la infancia, atravesamiento diferenciadores y elementos de convergencia entre generaciones.

Esta otredad que representa la infancia para la mirada adulta, ha sido ampliamente estudiada por Manfred Liebel (2018), al plantear que el problema se suscita en el caso de los niños/as, como grupo subalternos, su habla es deslegitimada y en los adolescentes se les considera como "descarados" e "indecorosos" a no ser que respondan a preguntas de los adultos. Es decir, su subalternidad se plantea en la invisilización por medio de falta de rescate de sus voces y también de su deslegitimación cuando se rescata.

Por otro lado, en el trabajo de Bravo-Segal y Villar (2020), que analiza los discursos de los medios de comunicación relacionados con los mayores, plantea que $71.4 \%$ presentan de manera desfavorable a los mayores porque los asocian a fallecimientos, deficiencias en la atención residencial y vulnerabilidad extrema. Las representaciones desfavorables contribuyen a generar prácticas discriminatorias hacia estos grupos. En la pandemia, los mayores es uno de los grupos más afectado, ya que suponía un mayor riesgo vital para estos grupos mientras que los niños y adultos jóvenes son proclives a contraer la enfermedad son menos proclives a desarrollarla de manera grave (Bravo-Segal \& Villar, 2020).

Es así como los medios de comunicación como usinas y operadores de la visibilidad de diferentes y diferenciadoras temáticas, han influido en el sentir social (Cebrelli y Rodriguez, 2013; Fiochetta, 2020; Bravo-Segal y Villar, 2020). A partir de lo planteado, en este trabajo se buscará identificar y analizar las representaciones sobre la niñez y la adolescencia en pandemia en la prensa local de Mendoza, Argentina.

\section{METODOlOGíA}

La metodología utilizada tiene un enfoque cualitativo de corte hermenéutico (Bolívar, 2020; Weiss, 2017). Para ello, se trabajó con fuentes periodística utilizando una como mojón principal: "Los Andes". Para contrastar y analizar la fuente anterior, se utilizaron fuentes locales "El Otro" e internacionales “El Confidencial”, “Les Echos” y “El País”.

El diario "Los Andes" es un medio local de la provincia de Mendoza Argentina. Este periódico fue fundado por Adolfo Calle el 20 de octubre de 1883 con el fin de “apoyar la campaña política de Rodolfo Zapata como diputado nacional en las elecciones de 1884, permaneció firme y poco a poco se transformó en un diario que se oponía a la prensa oficialista" (Campana, 2014, párr. 8). Se dispone a partir de dos soportes: papel y digital. Su acceso se realiza mediante repositorios digitales del propio diario, y en archivos y bibliotecas públicas de la provincia de Mendoza. Por último, el público al que el diario dirige su interés, se trata de lectores/as de sectores medios y altos y este filtro opera en la construcción de las noticias.

El criterio de selección estuvo orientado por las categorías específicas de nominar a las infancias: alumnos/as, chicos/as, menores, adolescentes, jóvenes, entre otras. Se seleccionaron 22 noticias del domingo de este periódico ya que se trata del día con mayor venta en relación a los demás días (Alcaraz y Madelaine, 2015; Garcimartin, 2015). Asimismo, la selección se procesó mediante el buscador en "Archivos" de la página web del diario: www.losandes.com.ar, y periodo que encuadro esta búsqueda fue del 1 de marzo y finaliza el 31 de diciembre de 2020. 
A partir de la selección anterior, se realizará un análisis de contenido tanto de los titulares como de los distintos elementos presente en una noticia (antetítulo, título, copete y contenidos). A su vez, se tendrá presente la jerarquización de las noticias otorgadas por el periódico, de manera tal que la importancia será distinta para las noticias en tapa que para aquellas que se encuentren en una sección interna del diario.

\section{RESULTADOS}

Las categorías emergentes filtradas a partir de las nominaciones de infancias son: 1. la escuela, 2. el confinamiento, 3. la salud infantil y 4. el femicidio infantil. Estas categorías se distribuyen en distintas temporalidades de aparición y colocadas en diferentes niveles de jerarquización de la información.

En cuanto a la temporalidad, el gráfico $N^{\circ} 1$ presenta la frecuencia de aparición de las noticias seleccionadas y los meses en que acontecieron en la prensa local.

Gráfico 1. Tiempo de aparición de noticias sobre infancias

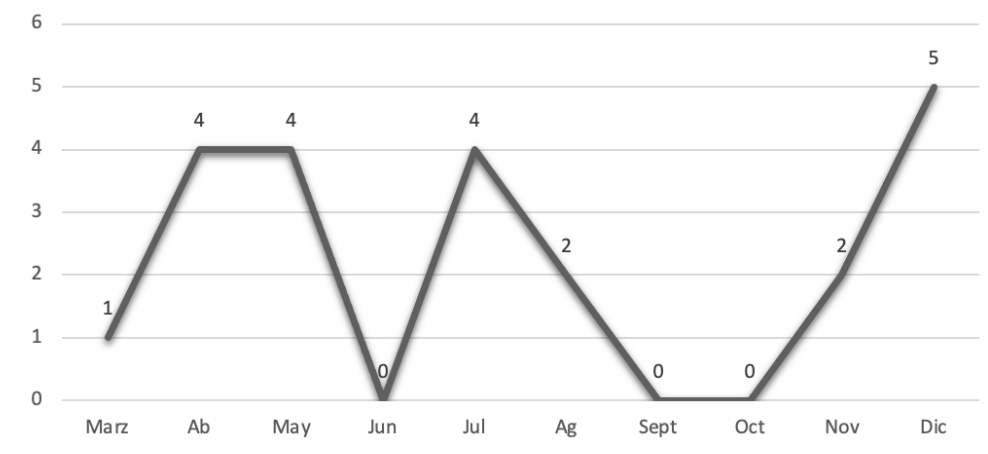

Fuente: elaboración propia a partir de Tabla $\mathrm{N}^{\circ} 1$.

En cuanto a la aparición de noticias sobre infancias, el mes con mayor cantidad de noticias fue diciembre (5), le siguen los meses de abril, mayo y julio con 4 noticias cada uno. Continuando con los meses de menor aparición son los meses de agosto y noviembre con 2 noticias cada uno. Por último, el mes de marzo es el mes con menos noticias (1).

Teniendo presenta las categorías emergentes, en la Tabla $N^{\circ} 1$ se podrá apreciar las categorías emergentes y los meses en que aparecieron dichas noticias, podemos decir que la categoría confinamiento, es las categorías más relevantes debido al Aislamiento Preventivo Social y Obligatorio (ASPO). La escuela, es la categoría con mayor frecuencia de aparición de noticias en el primer semestre, culminando con una única noticia que proyecta novedades para el año siguiente. La salud infantil, es una categoría focalizada de acuerdo a las consecuencias o secuelas específicas que puede dejar el COVID en bebés y la frecuencia de noticias comienzan después del hallazgo de dos recién nacidos cuyo testeo fue positivo para COVID. Por último, en cuanto al femicidio infantil, el mes de julio y diciembre acontecieron femicidios por los cuales la sociedad mendocina se vio conmovida por estos hechos. 
Tabla 1. Categorías emergentes en relación a los meses del 2020

\begin{tabular}{|l|c|c|c|c|c|c|c|c|c|c|c|}
\hline \multirow{2}{*}{$\begin{array}{l}\text { Categorías } \\
\text { emergentes }\end{array}$} & \multicolumn{7}{|c|}{ Meses 2020} & \multirow{2}{*}{ Totales } \\
\cline { 2 - 15 } & Mar & Abril & May & Jun & Jul & Ag & Sept & Oct & Nov & Dic & \\
\hline Escuela & & 2 & 2 & & 2 & & & & & 1 & 7 \\
\hline Confinamiento & 1 & 2 & 2 & & & 2 & & & 1 & & 8 \\
\hline Salud Infantil & & & & & 1 & & & & 1 & 1 & 3 \\
\hline Femicidio infantil & & & & & 1 & & & & & 3 & 4 \\
\hline Totales & 1 & 4 & 4 & & 4 & 2 & & & 2 & 5 & 22 \\
\hline
\end{tabular}

Fuente: elaboración propia

De acuerdo a la jerarquización mediática de las categorías sobre infancias, hemos encontrado que las noticias en tapa son 11, de las cuales 6 son noticia principal y 5 noticias destacadas. Las noticias en tapa se destacan por ser: a. noticia principal: aquella noticia que tiene centralidad en la primera página del diario; b. noticia destacada: figura en tapa en columna superior, lateral o inferior de la primera página del diario.

Otro nivel de noticia está dado por las noticias que no se encuentra en tapa, sino que se distribuyen en secciones. Las secciones en las que se han encuadrado las categorías son "Sociedad" y "Policiales". La sección "Sociedad" posee la mayoría de las noticias (9) mientras que en la sección "Policiales" solo 2 notas.

Tabla 2. Relevancia de las noticias según las categorías indagadas

\begin{tabular}{|l|c|c|c|c|c|}
\hline $\begin{array}{l}\text { Relevancia de la } \\
\text { noticia }\end{array}$ & Escuela & Confinamiento & Salud Infantil & Femicidio infantil & Total \\
\hline Tapa- Noticia principal & 2 & 3 & & 1 & 6 \\
\hline Tapa- Noticia destacada & 4 & & 1 & & 5 \\
\hline Sección Sociedad & 1 & 5 & 2 & 1 & 9 \\
\hline Sección Policial & & & & 2 & 2 \\
\hline
\end{tabular}

Fuente: elaboración propia

De esta manera, podemos destacar cómo en tiempos de confinamiento la mayor cantidad de noticias se plantea en la categoría confinamiento, pero en cuanto a la jerarquización de las mismas, la categoría escuela se plantea con mayor relevancia. Por otro lado, la categoría que tuvo mayor dinamicidad en cuanto a la jerarquización de la situación, es la de femicidio como hecho trágico que trascendió la sección Policiales para presentar como acontecimiento social en la provincia de Mendoza.

En lo próximo, se describirán las categorías según el contenido de las mismas.

\subsection{La escuela en pandemia: la era de la virtualidad y la desigualdad}

Las escuelas mendocinas comenzaron con el cambio de modalidad de presencial a virtual cuatro días antes del decreto que dictaminó el ASPO (20/3/20). La modalidad de enseñanza mediante educación a distancia comenzó a tener las vicisitudes propias de un cambio estructural hacia la virtualidad en un marco de desigualdad social. 
La escuela, en numerosas ocasiones, fue la noticia de tapa en los días de mayor tirada del periódico indagado. En la primera mención, se consultó a la Dirección General de Escuelas (DGE), que destacó que 37.000 niños/as y adolescentes (de un total de 370.000) tenía problemas de conectividad en un sondeo realizado a 55.000 docentes. Ante esta situación resolvieron enviarles cuadernillos con las tareas escolares. Sumado a lo anterior, se plantea que las familias de sectores medios y bajos poseen un dispositivo (celular) para completar las tareas y la comunicación con los docentes. También se plantea, la deficiencia en el acompañamiento de los niños/as y adolescentes con las tareas escolares debido a que la falta de conocimiento específico y necesario en ciertas actividades por parte de los miembros de las familias (De Vita, 2020).

Si bien, en el mes de abril, se destacó la desigualdad presente en los problemas de conectividad en familias de diferentes sectores junto con los problemas surgidos del nivel cultural de las familias en el acompañamiento específico de los saberes transmitidos. En el mes de mayo se trazaron nuevamente las dificultades económicas de las familias asociadas con la conectividad y se sumó un nuevo tema: los problemas vinculados con los niños/as que ingresan a nivel primario.

En la primera nota, se diseñan que los problemas ligados a la inequidad social hacen peligrar la educación virtual. Se plantea que las familias que no tienen WiFi gastan entre $\$ 1600$ a 2000 pesos en datos de internet, agravándose la situación porque la mayoría tiene celulares con planes prepago. Se informa que la DGE, mediante la plataforma Escuela Digital Mendoza, intenta acortar la brecha digital, específicamente en relación a sectores medios y bajos, aunque plantean que "llegar a todos es una tarea difícil" (Romanello, 2020a). De esta manera, se retorna a un dilema existente con anterioridad a la pandemia, la escuela no logra disminuir las desigualdades sociales en la vehiculización de la enseñanza-aprendizaje (Murrillo, 2016).

En la segunda nota, se plantea el argumento que los/as niños/as de primer grado "son los que más sufren" con esta modalidad (Fayad, 2020). Esta argucia no se sustenta a través de las fuentes consultadas como expondremos a continuación. En primer lugar, una de las entrevistadas plantea que los problemas no están tanto en el nivel primario como en el secundario. A esta contradicción se le suma una segunda que afirma que la modalidad "sirvió para revalorizar el contacto de los estudiantes con sus familias en el devenir educativo" (Fayad, 2020). La construcción de la nota, se conforma por fuentes familiares (padres/madres de niños escolarizados) y funcionarias de la DGE, quienes afirman con el mismo nivel de importancia, lo expuesto anteriormente.

Otra de las particularidades, se visibiliza en la construcción de la representación social: tiempo perdido-educación virtual. Las fuentes consultadas en la nota afirmaban lo siguiente: "Es un tiempo que no se ha perdido. Es recuperable. Seguimos trabajando, sólo que no tan rápido y evitando que todo sea lúdico porque después, cuando vuelvan a clases van a querer seguir jugando", "Creo que no es tiempo perdido. Me parece súper rico lo que se ha logrado [...]", "Para Silvina no es tiempo perdido porque se ha podido observar que en la educación hay una falencia grande en lo afectivo" (Fayad, 2020). Debido a lo expuesto nos preguntamos: la negación del tiempo perdido ¿es una recurrencia del/la entrevistado/a? ¿O realidad la pregunta periodística apuntaba a considerar que la virtualidad es tiempo perdido? De acuerdo con la construcción discursiva de la respuesta, a la negación del "tiempo perdido", se le añaden otras cuestiones como lo afectivo en la relación docente-alumno, en la riqueza de lo logrado hasta ese momento y en la modulación del tiempo más que en la pérdida. ¿Qué tiempo se pierde cuando las familias consultadas están en plena producción de acciones en la creación de lazos entre el conocimiento y la docente que lo viabiliza? ¿De qué maneras las acciones escolares en tiempo de cuarentena tienen menos valor que las acciones escolares en tiempos "normales"? Si nos inclinamos a pensar que es la respuesta a la pregunta del periodista, nos planteamos a continuación: ¿Qué sentidos contiene el constructo: 
educación virtual-tiempo perdido? Entre las posibles respuestas se encuentra la deslegitimación de la modalidad virtual mediante el menosprecio del trabajo creativo del docente en tiempos de excepción. También, entre las caras del prisma, podemos decir que la deslegitimación de "lo virtual” en sí mismo, se relaciona con el desdén hacia lo online, la virtualización de las relaciones y contenidos, entre otros elementos. Y sobre esta situación, destacamos las disputas que tiene/ tuvo el multimedio en su proceso de transición de diario impreso al contenido online:

Ayer se cumplió una nueva jornada de protesta sindical en las puertas del diario Los Andes, para exigir la reincorporación inmediata de los ocho trabajadores y trabajadoras despedidos por el Grupo Clarín, el pasado 16 de agosto [del 2017]. (...) reportero gráfico y dos periodistas que intempestivamente, y sin causa laboral, quedaron literalmente en la calle (Yañez, 2017). (Entre corchetes agregado por el autor).

En julio las notas estuvieron orientadas a la incertidumbre del cambio de modalidad de presencial a virtual. En la primera se afirma que la DGE apostaría por la modalidad semipresencial (Toledo, 2020) que consta de diversas modalidades: por turnos, por grupos o burbujas y hasta en lugares que no necesariamente serán los edificios escolares. Se detalla en esta nota que el cambio ha afectado tanto a alumnos/as como docentes, aunque en cuanto a lo digital el beneficio está del lado de los estudiantes que son "nativos digitales". En la segunda nota, presentada a fines de julio, se caracterizó por ser precuela del inicio de clases después del receso. Se plantea el retorno a la virtualidad: “todo será virtual” (Romanello, 2020b) ya que la situación epidemiológica para ese momento no era favorable. La preocupación para los/as docentes giraba en torno a 8000 estudiantes que estaban "poco conectados" o con más de 9 inasistencias mensuales. La desconexión se da por las siguientes razones: "en su zona no hay internet, no tienen un dispositivo para conectarse y les llegan las tareas en fotocopias. O porque les falta el apoyo familiar y les resulta más difícil la virtualidad" (Romanello, 2020b). También se consultó a un funcionario de la DGE que depositó la responsabilidad de la trayectoria escolar en las familias, "algún adulto en el hogar que esté encima de la educación del chico" (Romanello, 2020b). Resulta controvertido retornar a las viejas transferencias de responsabilidades cuando la desigualdad social y digital hacen peligrar la escolarización de los/as niños/as y adolescentes por falta de recursos económicos en tiempos de pandemia. ¿No tener $\$ 2000$ pesos mensuales para datos es falta de apoyo familiar? ¿Tener un celular por grupo familiar es no estar "encima” del niño/a o adolescentes en momentos de acompañamiento?

Las familias pobres resultan ser responsabilizadas por la trayectoria de los niños/as y adolescentes por parte del discurso estatal meritocrático. Por medio de la crítica, se plantea una linealidad causal donde la falta de recurso se supedita a la carencia de supervisión familiar para el logro educativo.

En diciembre se realizó una consulta a una funcionaria de la DGE quien afirmó que el 2021 las clases serán totalmente presenciales (Mateos, 2020). Esta aseveración la realiza con cierto optimismo y con ganas de volver a la presencialidad. En caso de retornar a la virtualidad, enmarcó la totalidad de responsabilidades en la Nación alegando que la Nación deberá establecer qué docente dará clases y con cuál protocolo se podrá asistir.

A partir de lo planteado anteriormente, y teniendo en cuenta lo expresado por Szulc et al. (2020) al afirmar que la escuela como espacio público destinado a la infancia [...] el cierre de los edificios escolares extrema esa invisibilización [de la infancia], ya que los estados no se han ocupado de generar otros canales de diálogo intergeneracionales" (p. 4). A lo expuesto Poggi, Serra y Carrera (2009 como se citó en Wenk, 2020) agregan que las significaciones culturales provenientes de las modalidades de invisibilización de la infancia o adultocentrismo, en sus diferentes variantes, 
son transmitidas a través de la escuela. Podríamos decir que para la infancia la escuela es la posibilidad del ejercicio de su ciudadanía, pero la protección adultista limita estas posibilidades a través del espacio simbólico en que el sitúan las perspectivas de las niñas/os y adolescentes.

Por otro lado, los modos de invisibilización de la infancia no son capital único del ámbito escolar, también el periódico local no rescató la palabra de los/as niños/as y adolescentes en relación a los asuntos que les conciernen. Es así, como los niños/as y adolescentes son “hablados” por la prensa local, al distinguir las imágenes sobre la infancia definidas en torno a la conexión (alumnos conectados-no conectados) y desigualdad tanto a nivel económico como cultural (niños/ as de sectores bajos y medio-bajos). Por otro lado, el diario presentó una imagen cargada de presunciones al colocar a los niños/as de primer grado como los más afectados por este cambio de la escuela, donde colocaron a este grupo falazmente en el inicio de la escolarización (se comienza la escolarización en sala de 4 años), buscando incidir en la sensibilidad social ("los chicos de primer grado son los más que sufren") bajo sus propios términos: "la modalidad de enseñanza en casa cuando debería ser en una escuela".

En segundo lugar, si bien, la modalidad de enseñanza es un cambio en la institución escolar, para algunos sectores la modalidad (presencial) era/es "la" institución escolar. La añoranza en la presencialidad, no permite establecer una evaluación crítica sobre la posibilidad real entre una mixtura entre la educación a distancia y la educación de modalidad presencial, en pospandemia. La ortodoxia social critica el cambio en la escuela invitando a volver a la presencialidad mediante la estrategia de la deslegitimación al docente. La defensa del establishment se corroboró cuando un periodista de LV10 criticó a los/as docentes en una entrevista a una representante gremial, afirmando que: "A mí me da la impresión de que ustedes quieren la pandemia eterna, quieren la pandemia eterna... Quedarse en sus casas, protestar desde sus casas, panza arriba... Se lo digo respetuosamente...” (Torrez, 2020 como se cita en Redacción El Otro, 2020).

En tercer lugar, la educación a distancia es un obstáculo para los inmigrantes digitales, pero no lo es para los nativos digitales. Según el estudio realizado por Joya Valbuena (2021) los valores, modos de encuentro y expresiones de una cultura se vehiculizan a través de la interacción por parte de las/os adolescentes con los contenidos de las plataformas y aplicaciones. Es decir que la cultura se virtualiza en el mundo adolescente. Quizás, el riesgo de introducir "lo digital” o virtual en las escuelas podría implicar un dilema para los adultos/as más que para los niños/as y adolescentes. Joya Valbuena (2021) afirma que las y los adolescentes, "como sujetos activos de la virtualidad, dejan de ser los "inexpertos" del adultocentrismo y pasan a ser los principales actores de un escenario que les constituye y que pueden agenciar con mayor autonomía que otros espacios de la cotidianidad" (Joya Valbuena, 2021). Transitar la pospandemia sin repensar/ reflexionar la modalidad de educar, podríamos calificarlo como un "pérdida de tiempo" valioso.

\subsection{El confinamiento y la casa como ámbito ambivalente de seguridad para la infancia}

El confinamiento fue una medida sanitaria adoptada por el gobierno argentino mediante el Decreto 297/2020 y consistió en permanecer en las residencias habituales, absteniéndose de recurrir a sus lugares de trabajo, no pudiendo transitar por “rutas, vías y espacios públicos” (Dec. 297/2020). Si bien se trató de una acción preventiva y pertinente para el cuidado de la población recomendada por la OMS, no estuvo absenta de repercusiones en los lazos sociales, en el desbalanceo de las rutinas y en la salud psíquica de la población, es decir los efectos colaterales del confinamiento. Sin embargo, la estrategia del confinamiento ha resultado ser más eficaz que la inmunidad de rebaño, que consiste en que continuar con la vida normal hasta que el contagio del $60 \%$ de la población genere los anticuerpos contra el virus (Mayordomo y Moreno, 2020). A continuación, 
se analizan la acción esperada después de confinamiento más estricto: las salidas de los/as niños/ as y adolescentes.

\subsubsection{Las salidas recreativas en niñez y la adolescencia}

La salida de la vivienda por parte de niños/as y adolescentes con fines recreativos no tuvo lugar en los titulares del medio masivo consultado. La mención estuvo de la mano de una reinterpretación realizada de una noticia de la agencia TELAM, por parte de la Redacción del diario Los Andes titulada: "Niños acompañados, distanciamiento y horario límite: cómo se podrá salir de paseo" (Redacción LA y TELAM, 2020). El paseo se protocolarizó de la misma manera que los reencuentros familiares. La "breve salida de esparcimiento" consistían en un juego rígido con reglas muy estrictas: 60 min, de día, hasta las 2ohs y no alejarse más de 500 metros del domicilio. ¿Qué adjetivos deberían tener los niños/as y adolescentes para este tipo de juego lineal y reglado? Acordamos con Magistris et al. (2020) que la recreación no es matar el tiempo, ni fue un premio después de 37 días de encierro. La recreación, incluso como derecho, debe atenderse con el fin de reducir las desigualdades ya que la diversidad de espacios para desarrollar las actividades no es el mismo para niños/as de sectores medios y altos que para los sectores populares.

Los juegos infantiles de plazas y parques estaban prohibidos según el Decreto №352/2020 desde el 19 de marzo en Mendoza capital. Si se rompía la prohibición primero se advertiría y luego, en caso de negativa, se recurrirá a la fuerza pública (adultos) y multa a los adultos responsables (en el caso de los "menores de edad"). La cinta señalizadora de "PELIGRO" fue el decorado de todos los juegos infantiles en las plazas donde estuvieran. ¿Cuál era el fundamento? Evitar la propagación del virus por medio del contagio. El desconcierto de las maneras en que el virus se propagaba instaba a realizar este tipo de prohibiciones. Continuando con los/as autores/as citados, acordamos con la necesidad de repensar lo público desde una perspectiva niña que genere condiciones para el ejercicio protagónico de sus derechos (Magistris et al. 2020).

Por otro lado, los/as adolescentes se resistieron al confinamiento. Teniendo en cuenta, que la adolescencia precisa del encuentro con los pares como parte de su construcción identitaria (Comité de Familia y Salud Mental [S.A.P.], 2020): el smartphone no bastaba para ese encuentro. También podemos decir que las casas para algunos/as adolescentes no representan un lugar de cuidado tanto por los "roces" como las violencias que pudieran acontecer (Llobet, 2020). Este dato es apuntado por Marisa Graham, Defensora de los derechos de niño/as y adolescentes, en una entrevista realizada por un periodista del Diario El País:

En las familias donde ya había violencia hay mujeres y niños conviviendo con un agresor. Hay que tener en cuenta que los violentos y los feminicidas tienen como modus operandi el aislamiento de sus víctimas. Y lo que sucede en esta situación extrema es que los factores de protección, como la escuela, no están, y los factores de riesgo, como el aislamiento, aumentan (Rivas Molina, 2020).

Sumado a lo anterior, se plantean otros tipos de violencias como aquellos actos que atentan contra la dignidad y salud integral de niños/as y adolescentes: abusos sexuales y maltrato, entre otros (Magistris, et al., 2020).

El espacio público en tiempos de confinamiento no fue un aliciente para los/as adolescentes. Esto fue lo que sucedió el día viernes 25 de septiembre del 2020 cuando "50 jóvenes se congregaron en la explanada de Casa de Gobierno con un solo reclamo en común: que se les permita patinar en skatepark municipal construido en Parque O’Higgins" (Cuello, 2020) y, luego, sin respuestas estatales, se trasladaron al Parque O'Higgins en la capital de Mendoza. Así fue cómo lo que podría haber sido un reclamo sin intervención policial -al igual que otros reclamos sucedidos en tiempos 
de pandemia a través de movilizaciones (por ejemplo "anticuarentenas")- terminó en la detención de 20 adolescentes practicantes de los deportes de: skate, parkour, bici entre otros. La policía reprimió con balas de goma y gas pimienta y los preventores - personal no policial-golpearon a los adolescentes con sus propias patinetas. El propio intendente de capital se manifestó sorprendido ya que, si bien mantenían "un diálogo fluido" -no aclara con quién-, estaban aprovechando la prohibición del uso de este tipo de espacios para hacer obras (Cuello, 2020). ¿Qué motivó al grupo de adolescentes a manifestarse en Casa de Gobierno? ¿Por qué no se consideraron interlocutores válidos de sus propios reclamos a los adolescentes y las autoridades se mantuvieron indiferentes? ¿Qué tensiones se disputan entre los adultos que tienen el monopolio de la violencia estatal y los adolescentes reclamando la apertura de un espacio público después de 183 días de ASPO?

Según Manfred Liebel (2018), “no hablar” para un grupo subalterno no significa que un sujeto no pueda articular sus propias necesidades e intereses, sino que su propio hablar no conduce a un diálogo con la clase hegemónica y nunca es escuchado ni siquiera es considerado por ella. En el caso de los niños/as, como grupo subalternos, su habla es deslegitimada y en los adolescentes se les considera como "descarados" e "indecorosos" a no ser que respondan a preguntas de los adultos.

\subsection{La infancia vulnerable: secuelas del COVID-19 en los niños/as.}

Según Donzelot (1979) en el siglo XIX se estableció paulatinamente el anclaje directo del médico en la célula familiar. En el siglo XX, después de las guerras mundiales, la salud de infancia comienza a representar un tema en la agenda pública a partir preocupación mundial de la mortalidad, morbimortalidad y pobreza en la infancia observada por los países centrales en los países en vías de desarrollo (Pilotti, 2001). De esta manera, la medicina se alió a las familias en el siglo XIX y la infancia en peligro comenzó a ser preocupación internacional en el siglo XX. La vulnerabilidad de la infancia, como categoría "aún no es..." (Verhellen, 2002), se ancla en la dificultad de pensar la autonomía de los niños/as y adolescentes (Liebel, 2018). Autonomía como posibilidad agencia de este grupo social y distanciado de los modos meritocráticos de pensar la sociedad.

En la provincia de Mendoza, la salud de la niñez recién nacida con COVID-19 positivo, tuvo mayor atención que la niñez y adolescencia en general. De acuerdo al estudio realizado, durante el segundo semestre comenzaron a aparecer con diferente nivel de importancia noticias periodísticas vinculadas al contagio de niños/as en Mendoza. El 5 de julio 2020 en el departamento de San Martín se contagiaron dos bebés con 7 y 23 días cada uno. El nexo epidemiológico se dio por el contacto de estrecho de las enfermeras neonatología quienes dieron positivo previamente (Redacción LA, 2020). La noticia tomó relevancia cuando desde la Dirección de Maternidad e Infancia desde donde se decidió comenzar a realizar un seguimiento de niños/as hasta dos años que hayan nacido infectados, para proporcionarles la salud adecuada y conocer su evolución. También se realizará el seguimiento a mujeres que hayan transitado su embarazo durante la pandemia.

El primer informe expone que de un total 143 mujeres embarazadas que dieron positivo para COVID, “9.3\% presentaron comorbilidades siendo las más frecuentes: obesidad, asma, hipertensión y ex fumadoras...” (De Vita, 2020a). Esta cifra se contrasta con otra afirmación aportada por la funcionaria entrevistada: "en el mundo ha habido casos de embarazadas que terminaron en cuidados intensivos. Sin embargo, esto ha estado asociado mayormente a patologías como diabetes, hipertensión, obesidad y en mayores de 40 años" (De Vita, 2020a). Tampoco se observan complicaciones en bebes por COVID, salvo aquellos que han tenido otras enfermedades de base. El seguimiento de recién nacidos y embarazadas generaría los recaudos preventivos necesarios ante secuelas producidas por COVID-19 en esta población. 
La última noticia fue 13 de diciembre del 2020 en primera plana y titulan que se: detectan a niños recuperados de Covid-19 que manifiestan secuelas. Son alrededor de 30 a 35 niños en el Hospital Notti con síndrome inflamatorio, que se trata de una secuela post-covid. La médica entrevistada "recalcó que el porcentaje es mínimo entre todos los chicos que tienen Covid-19" (De Vita, 2020b). Asimismo, agrega que "si bien es una enfermedad severa, tiene tratamiento y, en general, evolución favorable” (De Vita, 2020b).

Es importante reafirmar que la preocupación sanitaria por la infancia recién nacida puede generar acciones preventivas para la mortalidad materna e infantil. Sin embargo, las recomendaciones internacionales explicitan que las principales causas de mortalidad materna en el mundo se gestan por pobreza y abortos inseguros (Amnesty International, 2018).

\subsection{El femicidio que tuvo cara de niñas y adolescentes.}

El confinamiento, como medida de excepción producto del océano pandémico, contribuyó a la protección sanitaria ante un enemigo desconocido, pero en los casos de violencias que acontecen en espacios donde sucede el confinamiento, pudo resultar fatal. En el plano nacional, la Casa del Encuentro aportó los siguientes datos sobre los femicidios transcurridos durante los meses de marzo del 2020 a marzo del 2021: "el marco del ASPO/ DISPO, se produjeron 279 femicidios, 8 travesticidio y 20 femicidios vinculados de varones adultos y niños" (La Casa del Encuentro, 2021).

En el plano provincial según los datos aportados por la referente de MUMALA - Mendoza, Belén Bobba (se realizó una comunicación personal el día 23 de marzo del 2021, con el objetivo de consultar la situación de Femicidios en Mendoza durante el 2020), durante el año 2020 los femicidios fueron 11 de los cuales: 4 son femicidios directos, 3 vinculados con niñas/mujeres, 3 vinculados con niños/varones y 1 travesticidio. Según la edad de las víctimas podemos destacar que, entre femicidios directos y femicidios vinculados, la mayoría son personas menores de edad: Florencia Romano (14 años), Tatiana Guzmán (15 años), Aldana Gonzáles (16 años) y Sheila Ares (10 años). Según la cronología de los femicidios, esta travesía oscura comienza con el femicidio de Tatiana el 18 de julio del 2020 en el departamento de San Rafael y culmina con el femicidio de Florencia el 12 de diciembre del 2020 en el departamento de Maipú. En síntesis, podríamos decir que el femicidio en Mendoza durante la pandemia tiene una sensible inclinación hacia las niñas y adolescentes, abriendo y cerrando la cronología de violencias hacia las mujeres.

Por otro lado, de acuerdo al periódico consultado, los femicidios directos de Tatiana y Florencia tuvieron lugar en el día de mayor tirada del diario: el día "domingo". En el caso de Tatiana, la nota estuvo en la sección de "Policiales" el 18 de julio del 2020 y se tituló de la siguiente manera: Femicidio de la chica de 15 años en San Rafael: analizan si el detenido es imputable. Según lo explicitado en la nota Tatiana estuvo 11 días agonizando en el Hospital Schestakow, después que Diego Lea (acusado) le propinara cinco puñaladas después de resistirse a ser abusada sexualmente. Diego Lea era conocido de la familia de Tatiana y el 7 de julio a la tarde entró por la ventana de su vivienda donde consumó el crimen. En cuanto a Florencia, la situación tomó una relevancia diferente ya que "Ni una Menos Mendoza" levantó en las redes sociales la solitud de aparición de Florencia y el mensaje se viralizó. Fueron numerosas las marchas que solicitaban la aparición de Florencia. Después de 14 días de intensa búsqueda, el día 17 de diciembre del 2020, el hermano de Florencia le enviaba un mensaje a través de un video tomado por un periodista del diario Los Andes: "Estamos haciendo todo para que llegues a casa" (Los Andes Diario, 2020, 1m40s) y el abuelo de Florencia solicitaba a la justicia comprometerse con la búsqueda: "no estamos buscando un perrito, estamos buscando a mi nieta, es un ser humano" (Los Andes Diario, 2020, 1mo6s). El mismo día a las 13.50hs encuentran en una acequia el cuerpo calcinado de Florencia. 
Después del hecho el diario Los Andes dedicó tres notas el día domingo 20 de diciembre del 2020. Dos notas abordaron los detalles de la situación fatal: en la sección "Sociedad" titularon: Dejaron globos, flores y fotografías en el lugar donde hallaron el cuerpo de Florencia Romano; y en la sección "Policiales": "Engaño y muerte: las claves del femicidio de Florencia Romano que estremece a Mendoza". Ambas notas en distintas secciones orientan la complejidad del tema como un hecho policial que trascendió en un acontecimiento. Sin embargo, la orientación editorial del periódico destacó la relevancia del hecho en su variante política, es decir, la indignación social había producido hechos de violencia contra las instituciones estatales. En las fotografías se puede observar grafitis sobre las paredes de la Legislatura mendocina que decían: “Estado Femicida!!”; después la masiva movilización que tuvo lugar el día sábado. El título en primera plana del diario decía: "El gobierno ya identificó a los que causaron los incidentes" (Torrez, 2020, como citó en Redacción El Otro, 2020). El copete de la nota afirma que una veintena de manifestantes atacó las sedes de los tres poderes y se suma a lo anterior, que el femicidio produce una nueva "grieta" entre oficialismo y PJ. El femicidio es un hecho político, ya que se trata de "la denuncia a la naturalización de la sociedad hacia la violencia sexista" (La Casa del Encuentro, 2020), pero focalizarlo en una disputa electoralista y partidaria, se canaliza en una pelea conocida y no, hacia la búsqueda de un cambio en la estructura social patriarcal.

En cuanto al accionar de las instituciones, según el periódico consultado, se informa que la denuncia realizada el 13 de diciembre al código telefónico de emergencias 911 (CEO Centro Estratégico de Operaciones) por parte de un vecino, al instante en que se escucharon gritos en la casa del supuesto asesino. La operadora telefónica le cortó la comunicación por creer que se trataba de una broma, cuando en realidad se otorgaron todos los datos necesarios para acudir al domicilio (Zavala Tello, 2020). Existía una fuerte crítica hacia la búsqueda realizada por la policía y está refrendado por abuelo de la víctima, quien solicita mayor compromiso en la pesquisa de su nieta. Por último, explicitan que el domicilio donde sucedió la situación se encontraba dos cuadras de la comisaria. Lo cual, en la opinión de la comunidad, hacen que tomar mayor relevancia que el hecho se podría haber evitado. De esta manera, la operadora telefónica del CEO, los policías del rastrillaje y la comisaría cerca del domicilio del asesinato, sumado a las fotos de desconsuelo, impotencia, injusticia, desesperación después de encontrar el cuerpo Florencia en una acequia; determinan la culpabilidad compartida tanto por el acusado como por los actores estatales que no ofrecen el soporte social esperado.

Según lo detallan los datos referidos a las edades de las víctimas, Florencia, Aldana y Tatiana eran adolescentes y Sheila era una niña. Además, y según los datos aportados por las fuentes (La Casa del Encuentro, 2021), el femicidio en pandemia estuvo caracterizado por un mayor porcentaje de niñas y adolescentes. De esta manera, los espacios como la casa se transforman en amenaza para la reproducción de la vida y el cuidado (Llobet, 2020).

Por otro lado, también podríamos destacar que el aparato estatal y mediático, gestionan las miradas (Cebrelli \& Rodríguez, 2013) de los ciudadanos/as a través de la invisibilización de la infancia como víctima de femicidio, emplazadores de los sentires sociales caratulando en la tapa del diario los incidentes más que el hecho que lo motivó, tal como lo expresa Fiochetta (2020) en las marchas Ni Una Menos, y por último, reproduciendo la estructura patriarcal por medio de acciones y omisiones al momento de advertencias frente a los posibles caso de violencias.

\section{DISCUSIÓN Y CONCLUSIÓN}

El presente estudio tenía como objetivo identificar y analizar las representaciones sobre la niñez y la adolescencia en pandemia en la prensa local de Mendoza, Argentina. 
Los resultados demuestran que la infancia no solo es invisibilizada, sino que, regresivamente, retorna imágenes que se pretenden superar: la infancia moderna. Esta, a diferencia de la adultez, está relegada al espacio privado, cercana a la naturaleza más que a la cultura, tiene un fuerte componente irracional, es dependiente, incompetente y pasiva y, además, se desarrolla a través del juego (Prout 2005 como se citó en Liebel, 2018). Este tipo de representación coloca a la adultez en el centro de la evolución, donde la niñez es incompletud y la vejez es la espera paciente de la muerte.

La escuela y la familia como instituciones se vieron afectadas por las medidas sanitarias. La escuela permaneció cerrada y las viviendas se constituyeron en aulas. Es así como 636.000 niños/as y adolescentes estuvieron confinados/as haciendo tareas, pero también ayudando a sus padres/madres y con especial hincapié en las madres puesto que son las mujeres en las que recae la tarea de cuidado. Esta cotidianeidad femenina y cuidadora cargada de erosión no estuvo en la primera plana del periódico cuyo público preferencial son las familias de sectores medios y altos. La ortodoxia local invisibiliza también el cuidado en niños/as y adolescentes que cuidaban de sus hermanos/as, padres, madres y abuelos/as en caso de enfermedad y salud.

La crítica del establishment se dirigió a la modalidad de enseñanza virtual, cargando su crítica sobre los/as docentes, desconociendo el trabajo de los/as mismos/as realizado en el tiempo de modalidad virtual. A su vez, la configuración del constructo "pérdida de tiempo-educación virtual” es analogar la virtualidad a tiempo libre. De esta manera, la estigmación del/la docente como "vago/a" no se hizo esperar acusando a los/as docentes, desde la prensa local de eternizar la pandemia para "quedarse en sus casas, protestar desde sus casas, panza arriba" (Redacción El Otro, 2020). La estigmatización de los/as docentes es ante todo dañar el tejido social en sus soportes primarios.

Continuando con lo anterior, la modalidad virtual y la virtualidad en sí, es territorio de los nativos digitales (Prensky, 2001), de manera que, el movimiento realizado por la escuela -a través de los/as docentes- de lo presencial a lo virtual, podría capitalizarse como un modo de dialogo intergeneracional y de generación de nuevos espacios de intercambio (Szulc et all., 2020). Reflexionar sobre este aspecto, sería una oportunidad de conectar con aquello que los/as adolescentes y los niños/as consideran como “habitual” (Fernández Ruiz, 2021).

En el caso de las violencias hacia las niñas y las adolescentes, en el Estado local, tuvo una fuerte impronta patriarcal, sustentados por la ortodoxia mediática y política. Es por ello, que la sociedad se revela ante las instituciones estatales locales que se ausentaron u obstaculizaron los pedidos de ayuda y de protección hacia las niñas y mujeres. A pesar de ello, nos preguntamos lo siguiente ¿Qué categorías vinculadas a las mujeres han retrocedido debido a la pandemia? ¿Se han profundizado los vínculos violentos? ¿Se han ampliado las tareas de cuidado? ¿Los trabajos precarios de las mujeres han tenido mayor desvinculación laboral, debido a la caída de la economía? ¿Qué implica que el femicidio suceda después/durante el año de pandemia? ¿Por qué la mayor cantidad de femicidio directos y vinculados fue de niñas y adolescentes? Son preguntas que deberán retomarse por otras investigadoras/es y en otros estudios.

Las categorías de infancia regresivas se visibilizaron en el destino otorgado a la niñez y adolescencia en pandemia: el espacio privado (Llobet, 2020). Las imágenes referentes a la infancia moderna cuyo lugar o destino era el espacio privado. Los espacios públicos como paseos y plazas se constituyeron en prohibidos, sin tener presente la postergación del ejercicio del derecho de ciudadanía infantil. En el momento en el que el espacio público, ya no era un lugar prohibido, continuó la postergación. En el caso de la adolescencia local que decidió reclamar ante el Estado por la apertura del Parque O'Higgins (Cuello, 2020), obtuvo una respuesta violenta debido la 
deslegitimación de la voz adolescente y el silenciamiento represivo por parte del adulto Estado Municipal (Liebel, 2018).

Por otro lado, entendemos que la pandemia continuó silenciando la voz de los niños/as y adolescentes. En el caso de los/as adolescentes, el rompimiento de las restricciones sociales, constituye un fenómeno a estudiar. Comenzando por las relaciones entre el Estado y la adolescencia: ¿se sienten representados/as por los funcionarios y funcionarias políticas en cualquier polo partidario? Continuando por la educación sexual integral como herramienta aprendizaje y comprensión de sí y los demás, si estuviera correctamente ejecutada ¿sería un modo de contenerlos/as? La voz de las adolescencias ¿Qué tensiones compromete al interior de las fuerzas de seguridad? ¿Qué significa para un/a policía adulto/a no ser obedecido/a por un/a adolescente?

En cuanto a las limitaciones del proceso de investigación, podemos destacar que: si bien, se han podido configurar conclusiones solo extensibles al corpus seleccionado, se podría ampliar la selección teniendo presente estas dos sugerencias: 1. seleccionar más de un periódico local o nacional que permita diálogos entre las categorías emergidas, y 2. extender la selección de categorías a todos los días de la semana y no solo al domingo, lo cual podría brindar la trayectoria de las categorías en el transcurso de la semana. A su vez, es importante mencionar, que el archivo digital del diario es incompleto en cuanto a las tapas de diario que sube a su repositorio, así como, con la lectura exclusiva de las noticias para suscriptores/as del diario, cerrando la posibilidad de la lectura al público general. Ante ello, se realizó la búsqueda en el diario, la suscripción al diario al mismo y se investigó aleatoriamente por medio de diferentes buscadores generales de la web.

Por último, el femicidio de niñas y adolescentes, tanto directo como indirecto, es un tema a indagar con mayor profundidad. En este espacio, se ha presentado el fenómeno como una problemática asociada a la niñez y adolescencia, desde el cual es necesario investigar y generar medidas que atiendan a esta posibilidad real de terminar con la vida no solo de las mujeres adultas sino de las niñas y adolescentes.

Para finalizar, la invisibilización de la infancia es un dispositivo complejo que opera como una tecnología de exclusión social desde lo simbólico. La ausencia de las voces infantiles, de las infancias pobres y la punición sobre la palabra adolescente, reproducen experiencias de niñez y adolescencia donde la ciudadanía continúa siendo un ideal. La niñez y adolescencia como "los aún no" (Verhellen, 2002) y en clave moderna (Prout, 2005), son manifestaciones que en tiempos de pandemia se profundizaron, siendo sostenidas por la estructura patriarcal y adultocéntrica vigente. Esta regresión de categorías segrega, excluye y violenta a la niñez y adolescencia subalternizandola o provocando desenlaces fatales.

\section{REFERENCIAS}

Alcaraz, M., y Madelaine, N. (1 de octubre del 2015). Comment le week-end est devenu un temps fort des quotidiens. Les Echos. https://cutt.ly/smrF9Xs

Alcubierre Moya, B. (2018). De la historia de la infancia a la historia del niño como representación. En L. C. Lionetti, La historia de las infancias en América Latina. (pp. 15-32). Conicet, IGEHS.

Amnesty International (2018) Argentina: informe al Comité de los Derechos del niño de la ONU. 78th Session, 14 may-1 june 2018. London. https://www.amnesty.org/download/Documents/AMR1382552018SPANISH. pdf

Bolívar, A. (2020). Análisis del discurso y hermenéutica como métodos en la interpretación de textos. Interpretatio. Revista de hermenéutica, 5(1), 17-34. 
Bravo-Segal, S., \& Villar, F. (2020). La representación de los mayores en los medios durante la pandemia COVID-19: ¿hacia un refuerzo del edadismo? Revista Española de Geriatría y Gerontología, 55(5), 266271. https://doi.org/10.1016/j.regg.2020.06.002

Campana, C. (6 de julio del 2014). Adolfo Calle, el otro cuyano alborotador. Los Andes. https://losandes.com. ar/Adolfo-calle-el-otro-cuyano-alborotador/

Casas, F. (2006). Infancia y representaciones sociales. Política y sociedad, 43(1), 27-42.

Cebrelli, A., \& Rodríguez, M. G. (2013). ¿Puede (in)visibilizarse el subalterno? Algunas reflexiones sobre representaciones y medios. Revista Tram[p]as de la comunicación y la cultura (76), 89-99. https://cutt. ly/rmt9y 46

Comité de Familia y salud mental (2020) El estado emocional de las/os niñas/os y adolescentes a más de un mes del aislamiento social, preventivo y obligatorio. [SAP] Sociedad Argentina de Pediatría. https://cutt.ly/ omt7ecO

Cuello, R. (26 de septiembre del 2020). La marcha de skaters que terminó en máxima violencia: citarán a los preventores. Los Andes. https://cutt.ly/dmt7q89

De Vita, V. (1 de noviembre del 2020a). Estudiarán a embarazadas y recién nacidos con Covid-19 en Mendoza para medir efectos. Los Andes. https://cutt.ly/emytG79

De Vita, V. (13 de diciembre del 2020b). Detectan que niños recuperados de Covid 19 manifiestan secuelas cardiovasculares. Los Andes. https://cutt.ly/Jmyt2gx

De Vita, V. (5 de abril del 2020) Hay 37 mil chicos sin acceso a Internet para hacer las tareas en casa. Los Andes. https://cutt.ly/xmt49nM

Decreto 297 de 2020 [Presidencia de la Nación Argentina]. Por medio del cual se expide Aislamiento Social Preventivo Y Obligatorio, 19 de marzo de 2020. B.O. No. 34334.

Decreto 352 de 2020 [Intendencia de la Capital de Mendoza, Argentina]. Por medio del cual se prohíbe el uso de juegos y ejercitadores en paseos, parques y plazas en la provincia de Mendoza, 19 de marzo del 2020.

Donzelot, J. (1979). La policía de las familias. Ed. Pre-textos

Fayad, F. (10 de mayo de 2020) Alumnos de primer grado, los que más sufren los problemas de la escuela a distancia. Los Andes. https://cutt.ly/Emt40TT

Fernández-Ruiz, M. R. (2021). Nativos pandémicos: la educación virtual en Educación Infantil durante el confinamiento por COVID-19. Estudios sobre Educación. 10.15581/004.41.010

Fiochetta, M. (2020). Las manifestaciones de Ni Una Menos a través de los diarios argentinos. En E. Rodríguez Agüero, \& N. Encinas, Feminismos en la comunicación: medios, redes y artivismo al calor de la cuarta ola (págs. 65-84). Universidad Nacional de Cuyo. Secretaría de Ciencia, Técnica y Posgrado.

Garcimartin, M. (5 de octubre del 2015) El fin de semana es el gran aliado del periódico impreso. Media-Tics: información para gestionar el futuro. https://cutt.ly/Mmt32mk

INDEC (2013) Proyecciones provinciales de población por sexo y grupo de edad 2010-2040. Serie análisis demográfico $\mathrm{N}^{\circ} 36$. Instituto Nacional de Estadística y Censos.

Joya Valbuena, D. (2021) “'Nosotros nacimos con esto”': una aproximación a la virtualidad en la cotidianidad juvenil”. Trabajo Social 23 (1): 129-151. doi: https://doi.org/10.15446/ts.v23n1.88097

La Casa del Encuentro [@la.delencuentro]. (20 de Marzo de 2021). 20 de marzo 2021 En Argentina Periodo ASPO/DISPO. 279 femicidios, 8 transfemicidios y 20 femicidios vinculados de varones. [Flyer adjunto] Facebook: https://cutt.ly/xmrGdkp

Liebel, M. (2018). Infancias dignas, o cómo descolonizarse. Instituto de Formación para Educadores de Jóvenes (IFEJANT).

Llobet, V. (2020). El encierro de los niños y la distribución desigual de la precariedad. Sociedad e Infancias, 4, 283-284. https://doi.org/10.5209/soci.69632

Los Andes Diario. (s.f). Desesperado pedido de familiares de la adolescente desaparecida Florencia Romano [Archivo de Video]. Youtube. https://youtu.be/LEgRNgoVb28

Magistris, G., Macri, L., Morales, S., Vitale, L. y Almirón, G. (2020) Adultocentrismo y pandemia: qué lugar tienen las infancias. Riberas. Revista de la Universidad Nacional de Rosario. https://cutt.ly/Rmt863A 
Mateos, P. (6 de diciembre de 2020) Con la vista puesta en 2021, la DGE apuesta a las clases totalmente presenciales. Los Andes. https://cutt.ly/Imt807G

Mayordomo, C. y Moreno, S. (2020) De la inmunidad al confinamiento: dos paradigmas de una misma crisis. Más Poder Local. 41, pp. 42-43.

Murillo, F. J. (2016). Midiendo la Segregación Escolar en América Latina. Un Análisis Metodológico utilizando el TERCE. REICE. Revista Iberoamericana sobre Calidad, Eficacia y Cambio en Educación, 14(4),33-6o. https://www.redalyc.org/articulo.oa?id=55149101003

Pilotti, F. J. (2001). Globalización y Convención sobre los Derechos del Niño: el contexto del texto. Cepal.

Prensky, M. (2001). Digital natives, digital immigrants, part 1. On the horizon, 9(5), 1-6.

Redacción El Otro (10 de noviembre de 2020) Dale, hablemos de libertad de expresión. Diario El Otro. https://elotro.com.ar/dale-hablemos-de-libertad-de-expresion/

Redacción LA (26 de abril de 2020). Suárez autorizó las "salidas recreativas" en toda Mendoza: qué se podrá hacer y dónde Los Andes. https://cutt.ly/Rmt4tvu

Redacción LA y TELAM (26 de abril de 2020) Niños acompañados, distanciamiento y horario límite: cómo se podrá salir de paseo. Los Andes. https://cutt.ly/Wmt4LSS

Rivas Molina, F. (4 de mayo del 2020). Maltrato infantil, la amenaza silenciosa de la cuarentena en Argentina. El País. https://elpais.com/elpais/2020/04/29/planeta_futuro/1588161588_087511

Romanello, C. (24 de mayo de 2020a) Familias mendocinas gastan unos \$1.6oopor mes para tener datos y cumplir con la escuela. Los Andes. https://cutt.ly/amt4J19

Romanello, C. (26 de julio de 2020b) Empiezan las clases y se apuesta con todo a lo virtual. Los Andes. https://cutt.ly/cmt4Fq9

Szulc, A., Hecht, A., Enriz, N., García Palacios, M., Guemureman, S., Leavy, M. P., Varela, M., Cantore, A., Aveleyra, R., Morales, S., Frasco Zuker, L., Shabel, P., Taruselli, M., Aliata, S. y Parodi, C. (2020) Cuidado y escolarización de las infancias argentinas en tiempos de pandemia / Cura i escolarització de les infàncies argentines en temps de pandèmia. Revista AFIN. 126. pp. 1-8 https://ddd.uab.cat/pub/afin/ afinSPA/afin_a2021m1n126iSPA.pdf

Toledo, F. (5 de julio de 2020). No habrá clases normales en Mendoza en lo que queda del año. Los Andes. https://cutt.ly/lmt4mFE

Verhellen, E. (2002). La Convención Sobre Los Derechos Del Nino: transfondo, Motivos, Estrategias, Temas Principlales. Garant.

Weiss, E. (2018). Hermenéutica y descripción densa versus teoría fundamentada. En J. Hernández González y E. Weiss, Investigaciones educativas, (pp. 63-79). Bonilla Artigas Editores.

Wenk, E. R. (2021). El adultocentrismo en las decisiones judiciales cordobesas sobre asuntos que involucran a la niñez y adolescencia. Revista Argumentos. Estudios Transdisciplinarios Sobre Culturas Jurídicas $Y$ Administración De Justicia, (10), 115-132. https://cutt.ly/Pmt4h8K

Yañez, C. (24 de agosto del 2017) Diario Los Andes: el relato de los despedidos. El Otro. https://elotro.com. ar/diario-los-andes-el-relato-de-los-despedidos/

Zavala Tello, I. (13 de febrero del 2021) A dos meses del femicidio de Florencia Romano, elevaron la causa a juicio las pruebas que acorralan a Arancibia. Los Andes. https://cutt.ly/emyyXWr

\section{AUTOR}

José María Vitaliti. Doctorando en Ciencias Humanas y Sociales por la Universidad Nacional de Quilmes. Becario Doctoral del Consejo Nacional de investigaciones científicas y tecnológicas (CONICET). Licenciado en Minoridad y Familia por la Universidad del Aconcagua. Profesor titular de la cátedra de Estudios de Infancias en la Universidad del Aconcagua en provincia de Mendoza Argentina.

Conflicto de intereses

El autor informa ningún conflicto de interés posible.

Financiamiento

No existió asistencia financiera de partes externas al presente artículo.

Agradecimientos

$\mathrm{N} / \mathrm{A}$ 